\title{
Assessment of Mesophotic Coral Ecosystem Connectivity for Proposed Expansion of a Marine Sanctuary in the Northwest Gulf of Mexico: Larval Dynamics
}

\author{
Lysel Garavelli ${ }^{1,2 *}$, Michael S. Studivan ${ }^{2}$, Joshua D. Voss ${ }^{2}$, Alyson Kuba $^{3,4}$, \\ Joana Figueiredo ${ }^{4}$ and Laurent M. Chérubin ${ }^{2}$
}

\begin{abstract}
${ }^{1}$ Pacific Northwest National Laboratory, Richland, WA, United States, ${ }^{2}$ Harbor Branch Oceanographic Institute, Florida Atlantic University, Fort Pierce, FL, United States, ${ }^{3}$ ARC Centre of Excellence Coral Reef Studies, James Cook University, Townsville, QLD, Australia, ${ }^{4}$ Department of Marine and Environmental Sciences, Halmos College of Natural Sciences and Oceanography, Dania Beach, FL, United States
\end{abstract}

\section{OPEN ACCESS}

Edited by:

Michael Sweet

University of Derby, United Kingdom

Reviewed by:

Yoichi Miyake,

The University of Tokyo, Japan

Jonathan A. Anticamara,

University of the Philippines Diliman,

Philippines

${ }^{*}$ Correspondence:

Lysel Garavelli

lyselgaravelligmail.com

Specialty section: This article was submitted to

Coral Reef Research,

a section of the journal

Frontiers in Marine Science

Received: 21 February 2018 Accepted: 02 May 2018

Published: 22 May 2018

Citation:

Garavelli L, Studivan MS, Voss JD, Kuba A, Figueiredo J and Chérubin LM (2018) Assessment of

Mesophotic Coral Ecosystem Connectivity for Proposed Expansion

of a Marine Sanctuary in the Northwest Gulf of Mexico: Larval Dynamics. Front. Mar. Sci. 5:174. doi: 10.3389/fmars.2018.00174
In coral reef ecosystems, mesophotic coral habitat ( $>30 \mathrm{~m}$ to the end of the photic zone) are extensions of shallow reefs and contribute to the persistence of coral reef populations. In the North West Gulf of Mexico (NW GOM), the Flower Garden Banks National Marine Sanctuary (FGBNMS) is an isolated reef ecosystem comprising contiguous shallow and mesophotic reefs habitats on two central banks along the margin of the continental shelf. A future expansion of the sanctuary is proposed to include additional mesophotic banks and aims at building a network of protected areas in the NW GOM to ensure the persistence of the coral reef populations inhabiting the sanctuary. To evaluate the feasibility of this expansion and investigate the overall dynamics of coral species in the region, we studied the patterns of larval connectivity of Montastraea cavernosa, a common depth generalist coral species, using a larval dispersal modeling approach. Our results highlighted larval exports from the NW GOM banks to the northeastern and southwestern GOM, larval connectivity between all banks investigated in this study, and the potential for exporting larvae from mesophotic to shallower reefs. Our study associated with Studivan and Voss (2018; associate manuscript) demonstrates the relevance of combining modeling and genetic methods to consider both demographic and genetic timescales for the evaluation of the connectivity dynamics of marine populations. In the case of the NW GOM, both studies support the future management plan for expanding FGBNMS.

Keywords: mesophotic coral ecosystems, northwest Gulf of Mexico, Flower Garden Banks National Marine Sanctuary, Montastraea cavernosa, larval connectivity, sanctuary expansion, marine spatial planning

\section{INTRODUCTION}

Coral reefs ecosystems face severe degradation from local and global threats including overfishing, nutrient and sediment run-off, and climate change (Hoegh-Guldberg et al., 2017; Hughes et al., 2018). Worldwide bleaching events have contributed to global loss of coral cover and consequent decline of coral reef ecosystems (Gardner et al., 2003; Bellwood et al., 2004; Hughes et al., 2017). Despite the socio-economic importance of coral reefs, 
protection of these critical ecosystems remains limited. Most of the degradation has been documented in shallower reef ecosystems $(<30 \mathrm{~m})$, while deeper mesophotic coral ecosystems (MCEs) are projected to act as refugia and contribute to the persistence of coral reef populations (Glynn, 1996; Lesser et al., 2009; Bongaerts et al., 2010; Slattery et al., 2011; Van Oppen et al., 2011; Thomas et al., 2015). MCEs are light-dependent reef communities, standing between $30 \mathrm{~m}$ depth and the lower limit of the photic zone (Bongaerts et al., 2010; Hinderstein et al., 2010; Voss et al., 2014). In the Caribbean region, MCEs are hypothesized to be relatively less impacted by thermal stress and anthropogenic impacts as compared to shallower reefs (Bak et al., 2005; Menza et al., 2008).

In the northwest Gulf of Mexico (NW GOM), around $180 \mathrm{~km}$ off the coasts of Texas and Louisiana, coral reef ecosystems form dozen of banks mainly comprising mesophotic reefs along the margin of the continental shelf (Schmahl et al., 2008). Despite the extensive degradation of other ecosystems in the northern hemisphere, the coral cover in the NW GOM has remained relatively stable compared to other regions of the wider Caribbean (Aronson et al., 2005; Hickerson et al., 2012). This stability is mainly explained by low temperatures variations and high larval supply driven by the Gulf of Mexico Loop Current (Oey et al., 2005; Nunes et al., 2011; Rippe et al., 2017). Along the banks of the NW GOM, the coral diversity is relatively low. Among these banks, West and East Flower Garden Banks (FGB) include contiguous shallow and mesophotic reefs ecosystems (Schmahl et al., 2008). Reefs on West FGB and East FGB are described as some of the most pristine reef habitats and exhibit $50 \%$ to $80 \%$ coral cover, mainly massive brain and star corals (Hickerson et al., 2012; Johnston et al., 2016). Other banks such as Bright, Geyer, and McGrail Banks contain mesophotic habitats only and are mainly constituted of scleractinian and macroalgal communities.

In 1992, the FGB National Marine Sanctuary (FGBNMS) was created to protect the fish and benthic species living in this ecosystem. West FGB and East FGB were the first banks included in the sanctuary followed by Stetson Bank in 1996. Stetson Bank supports the least coral communities in the FGBNMS, with a coral cover of less than 8\% (DeBose et al., 2013; Johnston et al., 2016). Following extensive research in the NW GOM, a future expansion of the sanctuary has been proposed to include additional mesophotic reef banks (Department of Commerce, National Oceanic and Atmospheric Administration, 2015). This future management plan aims to build a network of protected coral banks in the NW GOM to ensure the persistence of the sanctuary's coral and fish populations.

To ensure the persistence of marine species and develop efficient management strategies such as the expansion of the FGBNMS, the assessment of larval connectivity is essential (Hastings and Botsford, 2006; Gaines et al., 2010; Burgess et al., 2014). For benthic species with a pelagic larval stage such as corals, larval connectivity depends on both biotic and abiotic processes such as hydrodynamic current, availability of spawning and settlement habitat, fecundity, larval behavior, larval pre-competency period, and larval duration (Pineda et al., 2007). Using a modeling approach, the influence of spawning periodicity, fecundity, dispersal duration, and time to competency have been shown to influence larval connectivity of coral species (Holstein et al., 2014, 2015a; Kough and Paris, 2015). However, those biological processes are not always known and are often complicated to estimate. In a recent study, Davies et al. (2017) modeled the larval dispersal in the FGB of Pseudodiploria strigosa, a scleractinian coral species with a short planktonic larval duration (PLD; 3 to 20 days). Their model did not predict larval export outside the FGB for this species and larvae released from the West FGB and East FGB had limited dispersal. Davies et al. (2017) based their results on virtual larvae passive surface transport only and their recruitment method did not include a pre-competency period, during which the larvae cannot settle, which would tend to overestimate local retention and underestimate long-distance dispersal.

In this study, we focus on Montastraea cavernosa, a common depth generalist, broadcast-spawning coral species. $M$. cavernosa is one of the most abundant coral species in the West FGB, East FGB, and in other mesophotic reef habitats of the NW GOM (Pattengill-Semmens et al., 2000; Voss et al., 2014). Its larval connectivity in the NW GOM and, in particular between the FGBNMS and potential additional protected banks, is unknown. By developing a biophysical model of larval dispersal for $M$. cavernosa among mesophotic reef banks in the NW GOM, we predict patterns of connectivity that may influence population persistence in this region. The model accounts for critical biotic and abiotic processes driving $M$. cavernosa larval connectivity both horizontally across banks and vertically between shallow and mesophotic reefs. To understand the overall dynamics of $M$. cavernosa in the region, this study 1 . Investigates the dispersal potential of $M$. cavernosa larvae in the GOM; 2. Determines the sustainability of $M$. cavernosa populations in the northwestern banks of the NW GOM by assessing its local connectivity patterns; and 3. Evaluates the larval exchange between mesophotic and shallow reefs by assessing the vertical connectivity in the West FGB and East FGB. The results are designed to serve as a basis for spatial management of $M$. cavernosa in the NW GOM.

\section{MATERIAL AND METHODS}

\section{Study Area}

Our study focuses on five banks located in the NW GOM, from west to east: West FGB, East FGB, Bright, Geyer, and McGrail (Figure 1). The former two are currently protected within FGBNMS and the later three are under consideration for protection in the pending FGBNMS expansion plan (Department of Commerce, National Oceanic and Atmospheric Administration, 2015). Stetson Bank (the third bank in FGBNMS) was not considered for this study due to its low coral cover (DeBose et al., 2013; Johnston et al., 2016). West FGB and East FGB are characterized by the presence of both shallow and mesophotic reefs habitat while Bright, Geyer, and McGrail Banks include mesophotic reefs only. 


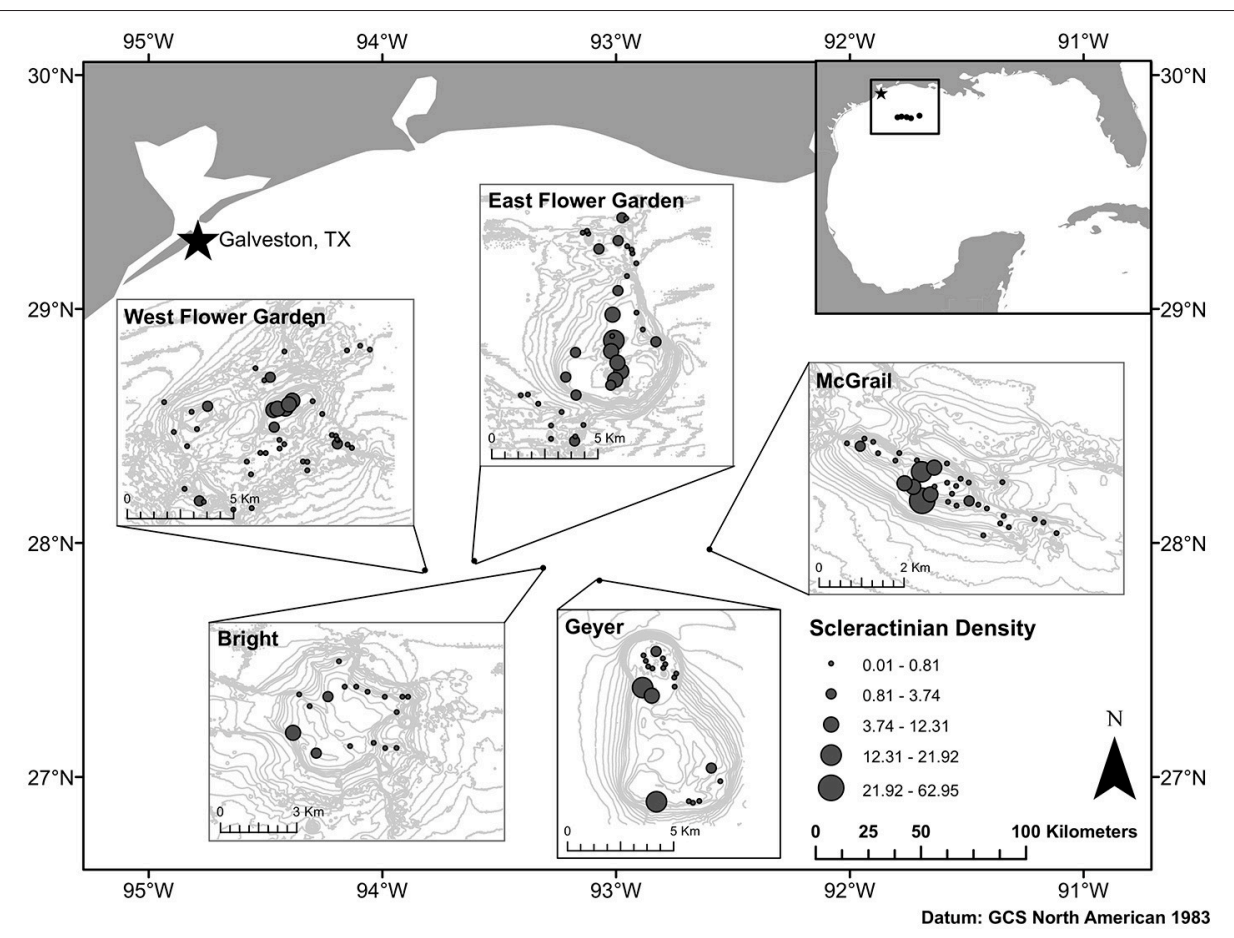

FIGURE 1 | Map of the northwest Gulf of Mexico showing the locations of five reef banks and the density of scleractinian (number of colonies by $\mathrm{m}^{2}$ ) for each bank. Banks from west to east: West Flower Garden, East Flower Garden, Bright, Geyer, and Mc Grail. The inset map shows the location of the five banks in the entire Gulf of Mexico.

\section{Hydrodynamic Model}

The Naval Oceanographic Office (NAVOCEANO) operates regional ocean prediction systems based on the Navy Coastal Ocean Model (NCOM; Barron et al., 2006). The Naval Research Laboratory developed NCOM, which is based on the Princeton Ocean Model with time invariant hybrid (sigma over Z) vertical coordinates. NCOM AMSEAS is a regional NCOM simulation whose domain covers the Americas Seas region including the Gulf of Mexico and the Caribbean Sea at 1/36 degree $(\sim 3 \mathrm{~km})$ horizontal resolution and is discretized over 40 levels in the vertical. The model topography comes from Naval Research Laboratory Digital Bathymetry Data Base 2-min resolution (NRL DBDB2). The atmospheric forcing fields are provided over this domain by a $15 \mathrm{~km}$ application of the Navy's Coupled Ocean/Atmosphere Mesoscale Prediction System (COAMPS ${ }^{\circledR}$ ) model. The AMSEAS ocean prediction system assimilates all quality-controlled observations in the region including satellite sea surface temperature and altimetry, as well as surface and profile temperature and salinity data using the NRL-developed Navy Coupled Ocean Data Assimilation (NCODA) system. Boundary conditions are applied from the NAVOCEANO operational 1/12 degree Global HYCOM (Chassignet et al., 2009). The model is forced by tides and discharges from 53 rivers in the region (Ko et al., 2003). NAVOCEANO distributes 3-h NetCDF files containing ocean temperature, salinity, eastward and northward currents, and elevation, along with the atmospheric forcing fields. The files are accessible from the National Centers for Environmental Information (NCEI).
AMSEAS time aggregated dataset is available from 2010 to present. The AMSEAS model has been deployed in response to the Deepwater Horizon oil spill event in 2010 (Zaron et al., 2015). A simulation was conducted using a Lagrangian particle tracker with random walk diffusion of archived AMSEAS data, with a particular focus on pollution pulses that penetrate into the estuaries east of the Mississippi River. This modeling formulation was capable of reproducing the oil spill transport (Zaron et al., 2015). This model was also used to predict likely drift tracks of sea turtles carcasses in the north central Gulf of Mexico (Nero et al., 2013). Surface currents and wind forcing used in estimating leeway and subsequent carcass drift backtracks were obtained from AMSEAS. In a similar manner, we used the velocity and density fields from AMSEAS in a biophysical model to simulate the transport of $M$. cavernosa larvae.

\section{Larval Dispersal Model}

To model $M$. cavernosa larval dispersal in the NW GOM, the individual-based offline Lagrangian tool Ichthyop v3.1 was used (Lett et al., 2008). The virtual larvae were represented as particles in three dimensions and characterized by their latitude, longitude, and depth at each time step of the model (i.e., $1 \mathrm{~h}$ ). In Ichthyop, the particles are advected by velocity fields generated by the NCOM AMSEAS hydrodynamic model. A forwardEuler advection was implemented in the model and horizontal diffusion was included following Peliz et al. (2007). The vertical diffusion coefficient was not included. Spawning and settlement habitat polygons were designed based on multibeam bathymetry 
data assembled from datasets of the United States Geological Survey, University of New Hampshire. Depth distribution of scleractinian coral at FGB was used to select spawning and settlement depths (Table 1). Our study focuses on 3 years: 2013, 2014, and 2015. These 3 years correspond to the same years during which Studivan and Voss (2018; associate manuscript) collected the coral samples used to assess the genetic population structure of $M$. cavernosa. To answer our study's objectives, different simulations were performed. Those simulations are detailed below.

\section{M. cavernosa Regional Larval Dispersal}

The goal of the first set of simulations was to investigate the dispersal potential of $M$. cavernosa larvae in the GOM. We created 19 polygons of $16 \mathrm{~km}^{2}$ representing the habitat of M. cavernosa in the NW GOM banks: 6 at West FGB; 7 at East FGB; 2 at Bright, Geyer, and McGrail Banks. Observations of spawning events in FGB showed that M. cavernosa spawning occurs around the first week after the full moon from July to September (Annual reports of coral spawning cruise, NOAA). The same features have been observed in the Caribbean and Bermudian reefs (Szmant, 1991). Over the polygons, 10,000 particles were randomly released in July, August, and September from 2013 to 2015. Releases occurred between 6 and 9 days after the full moon of each month (Acosta and Zea, 1997; Sammarco et al., 2004; Annual reports of coral spawning cruise, NOAA). In absence of data for the larval dispersal duration of M. cavernosa, we used data from another broadcasting scleractinian coral of the Caribbean region (Orbicella faveolata; Holstein et al., 2014, 2015a). The PLD was set to 20 days. (A sensitivity analysis was performed with 10 days of PLD and dispersal results were qualitatively similar). No data on larval behavior was available for $M$. cavernosa. We included a buoyancy scheme of the larvae in the model following Holstein et al. (2015a; Table S1.1). M. cavernosa larvae positions were recorded at the end of their modeled dispersal to estimate their putative destination in the GOM. The mean larval dispersal distances were calculated from their release to their destination locations.

\section{M. cavernosa Local Larval Connectivity}

The goal of the second set of simulation was to assess $M$. cavernosa local larval connectivity patterns in the banks of the NW GOM. The same modeling approach was used as for the first set of simulation. The main difference here is the incorporation of settlement habitat. The 19 polygons previously described (i.e., 6 at

TABLE 1 | Minimum and maximum spawning and settlement depths (i.e., depth range; in $\mathrm{m}$ ) for each bank of the study area.

\begin{tabular}{lc}
\hline Banks & Depth range $(\mathbf{m})$ \\
West FGB & $18-112$ \\
East FGB & $16-110$ \\
Bright & $33-84$ \\
Geyer & $50-90$ \\
McGrail & $45-87$
\end{tabular}

West FGB; 7 at East FGB; 2 at Bright, Geyer, and McGrail Banks) were used as both release and settlement areas for $M$ cavernosa larvae. Biological parameters of $M$. cavernosa larvae are the same as in the first set of simulation. The main difference with the first set of simulation was the addition of a larval pre-competency period in the model. The duration of 3.97 days of pre-competency period was chosen based on larval experiments results (data obtained from laboratory experiment, Supporting Information S1, Figure S1.1). Over the 19 polygons representing release areas, 10,000 larvae were randomly released in July, August, and September from 2013 to 2015. The simulated larval dispersal lasted for 20 days (i.e., duration of PLD; A sensitivity analysis was performed with 10 days of PLD. Connectivity patterns were qualitatively similar and values were slightly higher with shorter PLD.). During their dispersal, larvae located in a settlement area and that were at least 3.97 days old were considered settled in the model.

To predict the larval connectivity patterns of the species between release and settlement areas of the NW GOM banks, the outputs of the model simulation were analyzed in connectivity matrices. Values of the connectivity matrix represent the larval transport success $C_{i, j}$ from release polygon $i$ to settlement polygon $j$. In order to account for the coral fecundity in the model, we used density data of scleractinian coral species collected in each bank (see Voss et al., 2014 for methods; Figure 1). The coral density was then estimated in each habitat polygon of the model. The rows of the connectivity matrix (i.e., release areas) were multiplied by the estimated density of coral in each polygon. Monthly larval transport success was averaged between all the banks and compared for each year of simulation to assess the monthly and annual variability of $M$. cavernosa larval connectivity patterns. To calculate larval exchanges of $M$. cavernosa between potential subpopulations and identify approximately independent subpopulations or metapopulations (i.e., connected subpopulations), we applied a clustering method developed by Jacobi et al. (2012). The method consists of dividing the study area into a finite number of mutually exclusive subpopulations based on minimization of an objective function that calculates larval exchange between potential subpopulations using the connectivity matrix. The connectivity matrix used was the average per bank and over the 3 years of study $(2013,2014$, and 2015).

\section{M. cavernosa Vertical Larval Connectivity in West FGB and East FGB}

The goal of the third set of simulations was to assess the larval vertical connectivity between the shallow and mesophotic reefs of the West FGB and East FGB. Those two banks have the deepest mesophotic reefs in the region (112 $\mathrm{m}$ for the West FGB and $110 \mathrm{~m}$ for the East FGB). Coordinates of the polygons previously defined for the West FGB and East FGB were used. Polygons representing shallow reefs of the FGB were set between 18 and $30 \mathrm{~m}$ depth for the West FGB and between 16 and $30 \mathrm{~m}$ depth for the East FGB. Polygons representing mesophotic reefs were set between 31 and $112 \mathrm{~m}$ depth for the West FGB and between 31 and $110 \mathrm{~m}$ depth for the East FGB. Over these polygons 
representing both shallow and mesophotic reefs in the West and East FGB, 10,000 larvae were randomly released in July, August, and September from 2013 to 2015 for a duration of 20 days (i.e., duration of PLD). During their dispersal, larvae located in one of the polygons and that were at least 3.97 days old were considered settled in the model. The biological parameters of $M$. cavernosa were similar to the previous detailed simulations.

To predict the larval vertical connectivity patterns of $M$. cavernosa between the shallow and mesophotic reefs of West FGB and East FGB, the outputs of the model simulation were analyzed in connectivity matrices. The results were averaged over the 3 years of simulation.

\section{RESULTS}

\section{Regional Larval Dispersal in the NW GOM}

For all 3 years of simulation, larval abundance was higher close to the NW GOM banks, i.e., all of the banks used in the simulation (Figure 2). Generally, larvae remain in the northern part of the GOM although none was transported north onto the continental shelf. However, direction of the larval transport differs depending on the year. While larvae are mainly exported southwest of the release banks in 2013 (Figure 2A; mean larval dispersal distance $=54.4 \pm 46.3 \mathrm{~km}$ ), they follow a northeastern path along the northern shelf of the GOM in 2014 and 2015 (Figures 2B,C; mean distance $=203.4 \pm 133.5 \mathrm{~km}$ for $2014,212.6 \pm 146 \mathrm{~km}$ for 2015). In the last 2 years of simulation, larval trajectories split into two branches from around the Mississippi river delta $\left(29^{\circ} \mathrm{N}\right.$, $\left.89^{\circ} \mathrm{W}\right)$. The maximum distance of larval dispersal was $731.7 \mathrm{~km}$ in 2014 (it was $458.2 \mathrm{~km}$ in 2013 and $646.7 \mathrm{~km}$ in 2015).

\section{Local Larval Connectivity Between Banks}

The model predicts significant yearly and monthly variability in larval transport success (Figure 3). In 2013, larval transport success was overall $2.2 \%$ and higher than in the other years $(0.7 \%$ in 2014; $0.94 \%$ in 2015). Monthly variability was mostly observed in 2013. Larval transport success was lower in August than in July and September (2.51\% in July; $0.65 \%$ in August; $3.44 \%$ in September). This tendency was also noted for 2015 (1.01\% in July; $0.69 \%$ in August; $1.11 \%$ in September). In 2014, transport success was higher in July compared to August and September $(1.10 \%$ in July; $0.61 \%$ in August; $0.40 \%$ in September).

Larval connectivity patterns for $M$. cavernosa between banks exhibited interannual variability (Figure 4). The model predicted larval settlement in all the banks. The lowest larval transport success was toward the West FGB and the highest toward McGrail. As previously observed, a decrease in larval connectivity was noted in 2014 compared to the other years. East FGB (mainly
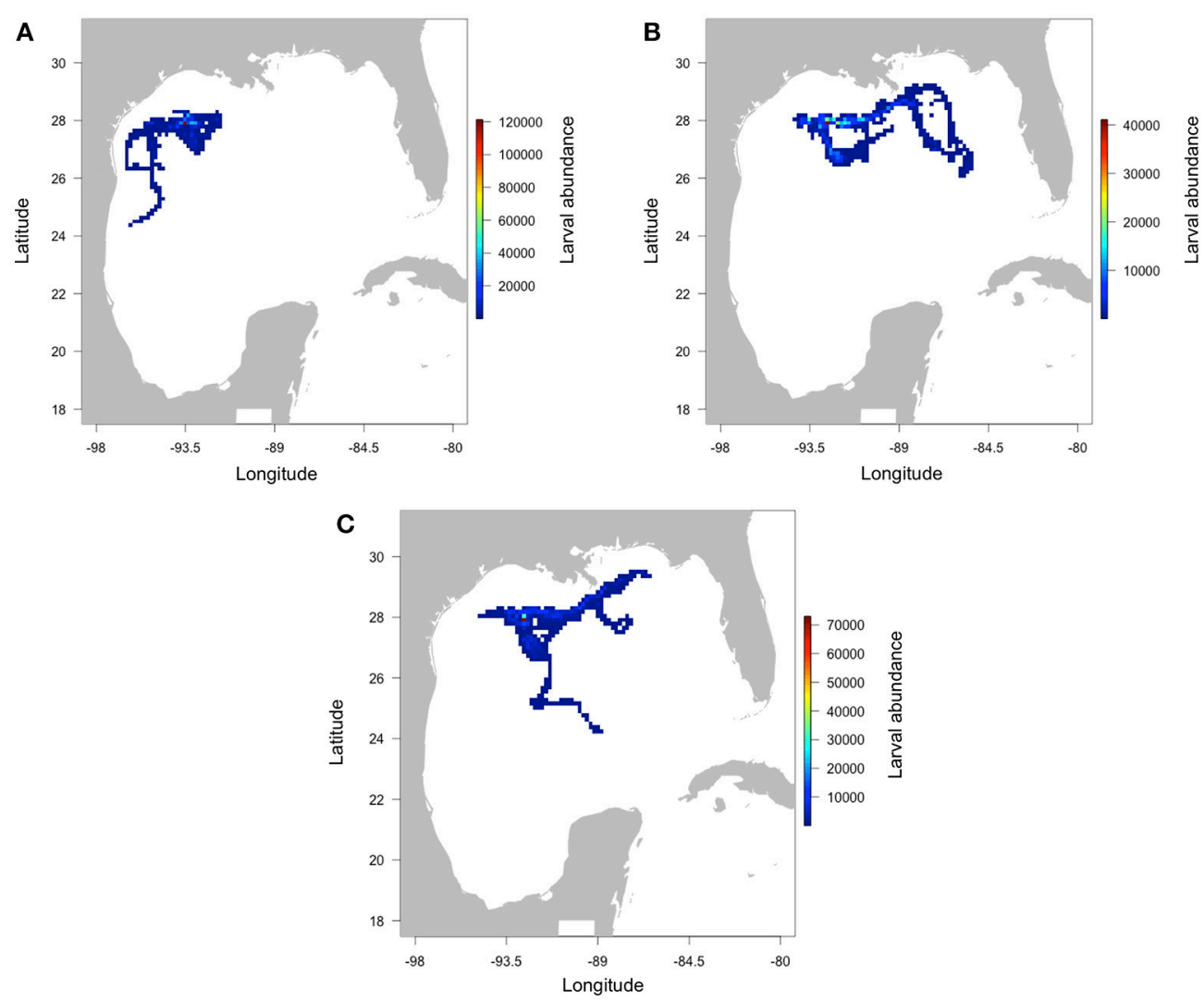

FIGURE 2 | Predicted larval abundance of $M$. cavernosa in the Gulf of Mexico after release from the banks (West FGB, East FGB, Bright, Geyer, Mc Grail; see Figure 1 for the location of each bank) for the years 2013 (A), 2014 (B), and 2015 (C). The number of larvae was summed inside a grid cell of $0.15 \times 0.15^{\circ}$. 


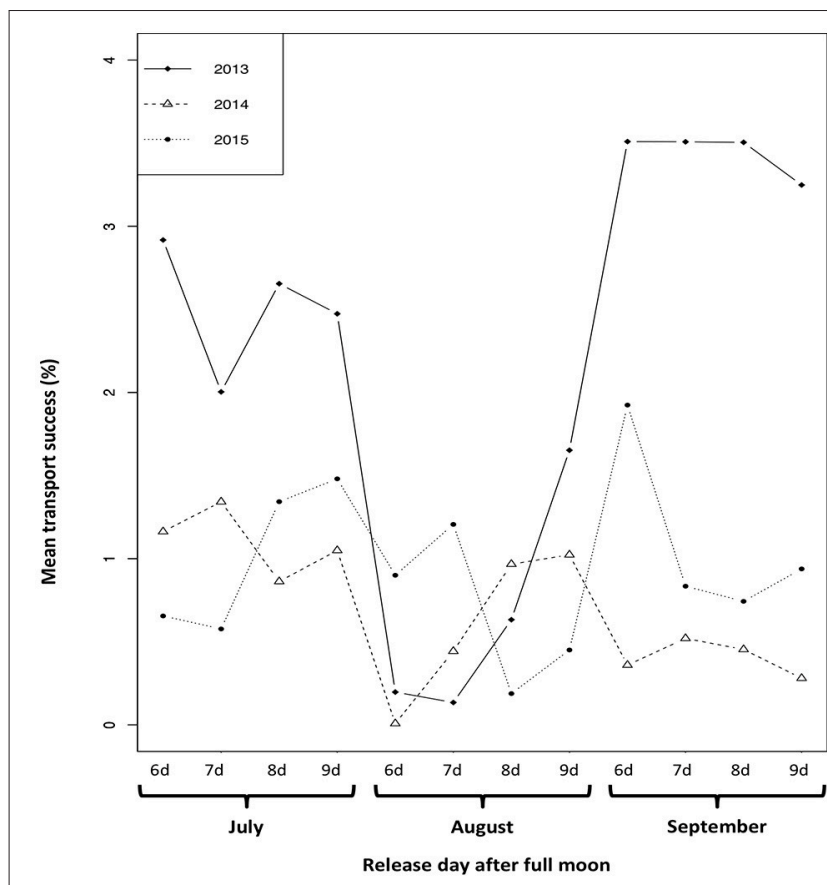

FIGURE 3 | Mean transport success (percentage) of $M$. cavernosa larvae per month and year of release averaged over West FGB, East FGB, Bright, Geyer, and Mc Grail. in 2013) and McGrail are the banks where to larvae were the most transported, mostly coming from West FGB, and the West FGB, East FGB, and Bright, respectively. Local retention (larvae settling on the same bank where they were released) is higher in 2013 compared to 2014 and 2015 (0.72\% in 2013; 0.17\% in 2014; $0.009 \%$ in 2015). In 2013, local retention is higher in East FGB (1.15\%) and McGrail (1.52\%). It is null in both 2014 and 2015 in the West FGB and McGrail. The clustering method applied to our connectivity results suggests that all the banks belong to the same metapopulation.

\section{Vertical Larval Connectivity in the West FGB and East FGB}

Vertical connectivity of $M$. cavernosa was investigated for the 3 years of simulation in the West FGB and East FGB (Figure 5). Globally, more larvae settled in the mesophotic reefs than in the shallow reefs for both banks (mean transport success to mesophotic reefs $=3.84 \%$; mean transport success to shallow reefs $=0.44 \%$ ). Larval transport was also mostly unidirectional from the West FGB to the East FGB. The mesophotic reefs of the East FGB received the most larvae from both shallow and mesophotic reefs of the West FGB. Local larval retention was higher inside the East FGB (from shallow and mesophotic reefs toward mesophotic reefs; $1.15 \%$ ) than inside the West FGB $(0.32 \%)$ and higher in the mesophotic reefs for both banks $(0.43 \%$ in mesophotic reefs vs. $0.02 \%$ in shallow reefs).

\section{DISCUSSION}

The biophysical larval dispersal model developed for $M$. cavernosa in the NW GOM highlighted larval exports from the NW GOM banks to the northeastern and southwestern GOM, larval connectivity between all banks investigated in this study, and the potential for exporting larvae from mesophotic to shallow reefs.

The larval dispersal model predicted large-scale larval dispersal of M. cavernosa outside the NW GOM banks. Larvae were transported from the northwestern to the northeastern GOM in 2014 and 2015. Predictive likelihood of habitat for mesophotic coral in the GOM shows potentially suitable depths and benthic composition for scleractinian coral along nearly all of the outer continental shelf (Kinlan et al., 2013). In 2014, we found that larvae could be transported as far as $731.7 \mathrm{~km}$ despite a relatively short PLD of 20 days. In the NW GOM, the banks investigated in this study could serve as larval sources for MCE that fall within the area of possible dispersal such as Pinnacles Reef Trend and Florida Middle Grounds (Locker et al., 2010).

$M$. cavernosa subpopulations in the NW GOM banks selected in this study were connected at least once between each other through larval dispersal. The overall patterns of $M$. cavernosa larval connectivity in the NW GOM banks can be described as a main transport from the western banks to the eastern banks with few dispersal events in the opposite direction. However, connectivity patterns were considerably variable intra and interannually. Year 2013 showed the highest local larval transport success in July and September, consequently the shortest range of larval transport, which is to the west of the banks. In contrast, years 2014 and 2015 show the longest transport range and in both years, it is eastward and south along the shelf break in 2015 or southeast from the banks in 2014.

The variability of $M$. cavernosa larval dynamics patterns could be explained by the variability in direction and magnitude of oceanic currents in the NW GOM. The surface circulation in the NW GOM is dominated by the northern extent of a persistent western boundary current that flows eastward along the continental shelf break. In addition, the impingement of Loop Current Eddies (LCEs), and their cyclonic counterpart is a major driver of the variability of the western boundary current (Vukovich and Crissman, 1986; Sutyrin et al., 2003). Shoreward of the western boundary current, over the broad Louisiana-Texas shelf (LaTex), the flow is relatively weak, generally cyclonic, and largely driven by wind stress. The annual variability between larval dispersal patterns obtained in 2013 and the other two years (2014 and 2015) is due to the lack of impingement of LCEs and cyclonic counterparts on the LaTex shelf break, as shown in Figure 6. In July 2013, FGB is filled with submesoscale features (Figure 6A) favorable to local larval transport, while in July 2014 and 2015, unbroken mesoscale vorticity filaments replaced these features and are associated with relatively strong along-shelf currents leading to longer larval dispersal distances (Figures 6B,C). LCEs (cyclones) impingement on the LaTex and Mexico-Texas shelves drives strong eastward (westward) flows along the LaTex shelf break that replaced the submesoscale features seen in summer 2013 (Figure 6A), enhancing remote 


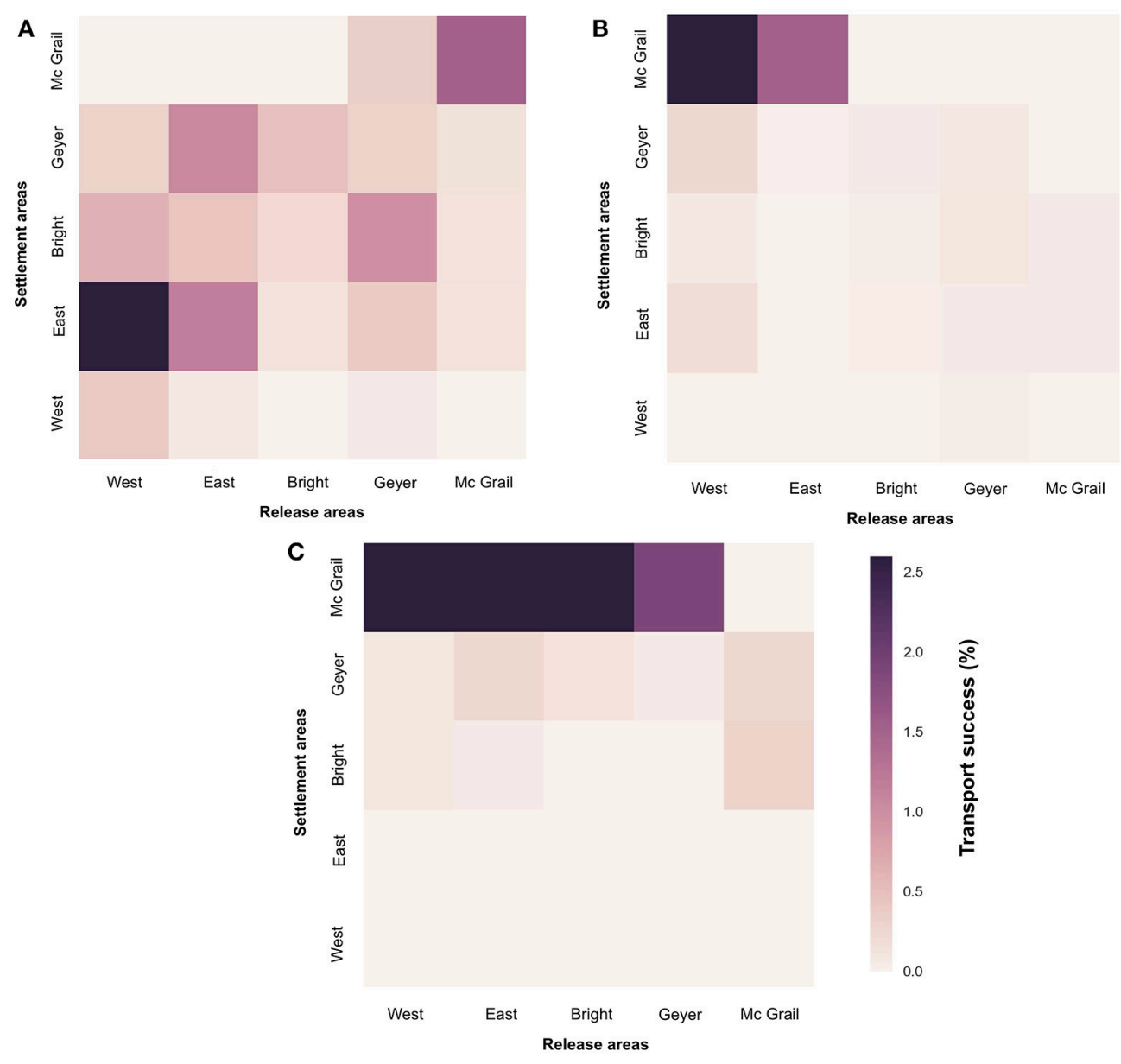

FIGURE 4 | Connectivity matrices representing the percentage of transport success of $M$. cavernosa larvae from release to settlement areas in the banks (West FGB, East FGB, Bright, Geyer, Mc Grail) for the years 2013 (A), 2014 (B), 2015 (C).

along-shelf transport and cross-shelf transport in eddies. The 2013 transport pattern is characteristic of that region as revealed by climatological Lagrangian Coherent Structures (cLCS) in Gough et al. (2018). This pattern is likely to be driven by the sub-mesoscale features found near the shelf break (Figure 6). In 2014 and 2015, cross-shelf export is localized in the region of the hook-like cLCS pattern identified in Gough et al. (2018) and seems to be associated with significant eddy driven alongshore currents. Significant eddy impingement on the NW GOM is thus identified as one of the drivers of long-range dispersal of coral larvae from the NW GOM banks to the eastern GOM. Such eastward dispersal events have been previously described around the FGB in 1997 and 1998 (Lugo-Fernández et al., 2001). Persistent Lagrangian patterns in the NW GOM identified by Gough et al. (2018), who used 18-year average flow field data (1995-2012), suggest that short westward dispersal near FGB has been most likely to occur as observed in Davies et al. (2017).

The unidirectional larval transport from West FGB and East FGB to Bright, Geyer, and McGrail arises the question of sufficient larval supply inside West FGB and East FGB. For both West FGB and East FGB, larval dispersal from mesophotic reefs to shallow reefs was predicted, supporting the role of mesophotic reefs as larval sources for shallower reefs (Lesser et al.,
2009; Slattery et al., 2011; Holstein et al., 2015a,b). However, contrasting spatial patterns of vertical larval connectivity between West FGB and East FGB were also observed. The most significant pattern of vertical larval exchanges was a cross-vertical connectivity from the West FGB toward the East FGB. Both shallow and mesophotic reefs of the West FGB were exporting larvae to the East FGB. The low larval connectivity toward the East FGB from the other banks considered in this study and previously observed may be counterbalanced by the local retention in the East FGB and the vertical larval exchanges from the West FGB, and be sufficient to sustain the populations of $M$. cavernosa in the area. Also, including other mesophotic reefs located southern of the area in the analysis could offset the low larval transport success toward West FGB.

Although banks of the NW GOM are relatively spatially close the ones from the others, local retention in the area and larval connectivity between banks were low. However, all the banks were predicted to belong to the same metapopulation. Therefore, recurrent larval exchanges between banks may be sufficient to allow the sustainability of $M$. cavernosa populations in this region, although it is isolated from other MCEs. Both the larval dispersal model from our study and genetic data from Studivan and Voss (2018; associate manuscript) suggest 


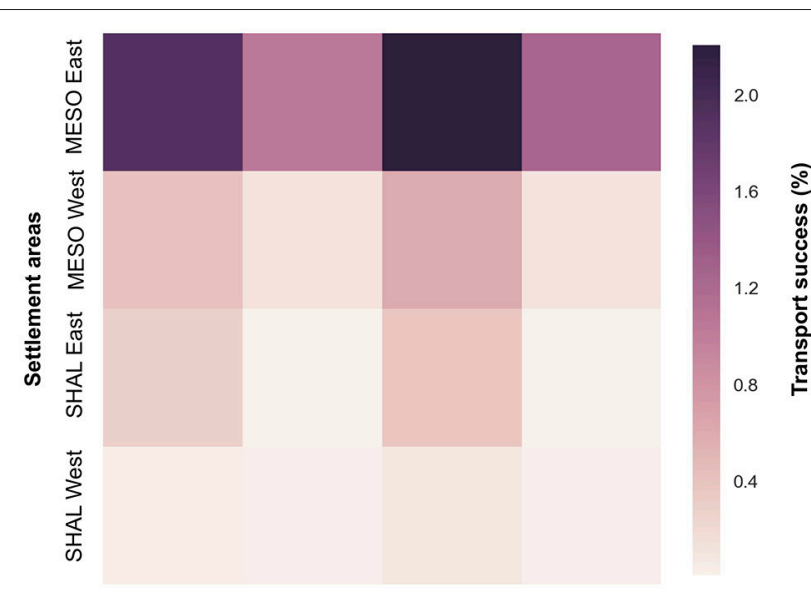

SHAL West SHAL East MESO West MESO East

Release areas

FIGURE 5 | Connectivity matrices representing the mean percentage of vertical transport success of $M$. cavernosa larvae between shallow (18-30 m depth for West FGB and 16-30 m depth for East FGB) and mesophotic (30-112 $\mathrm{m}$ depth for West FGB and 30-110 m depth for East FGB) reefs in the West and East FGB for the 3 years of simulation (2013, 2014, and 2015). SHAL, shallow; MESO, mesophotic.

that the NW GOM is well mixed. However, genetic data also showed a downstream to upstream net migration likely explained by the seasonal freshwater westward transport over geological timescales (Oey et al., 2005; Schmahl et al., 2008). The difference in findings between our study and Studivan and Voss (2018; associate manuscript) study is most likely due to the short integration time (i.e., demographic) vs. long (i.e., genetic) timescales, which happened to encompass 2 years over three of intense eddy impingement, which yielded the eastward larval transport. Given the possibility that individual coral colonies can live hundreds of years, a relatively rare larval dispersal event from one bank to the other is likely enough to observe low population differentiation between two banks. More importantly, the results from the demographic (this study), and genetic Studivan and Voss (2018; associate manuscript) connectivity suggest that the reduced demographic connectivity is sufficient to sustain high genetic connectivity between all banks.

Notwithstanding, our biophysical model was used only to provide a snapshot of the larval dynamics of $M$. cavernosa in some of the northwestern MCEs of the GOM. Considering what seem to be the recent yearly variability of the larval connectivity patterns and of the accrued eddy impingement in the region, eastward dispersal events similar to the ones described here may occur more often in the future. The singularity of our results suggests that the years selected were atypical, in particular 2014 and 2015. Our results' annual variability highlights the necessity to perform modeling studies over enough years, particularly in small-scale larval dispersal studies, in order to smooth the effects rare events (Holstein et al., 2015a; Kough and Paris, 2015; Chérubin and Garavelli, 2016; Davies et al., 2017). Furthermore, because of a lack of available larval biological
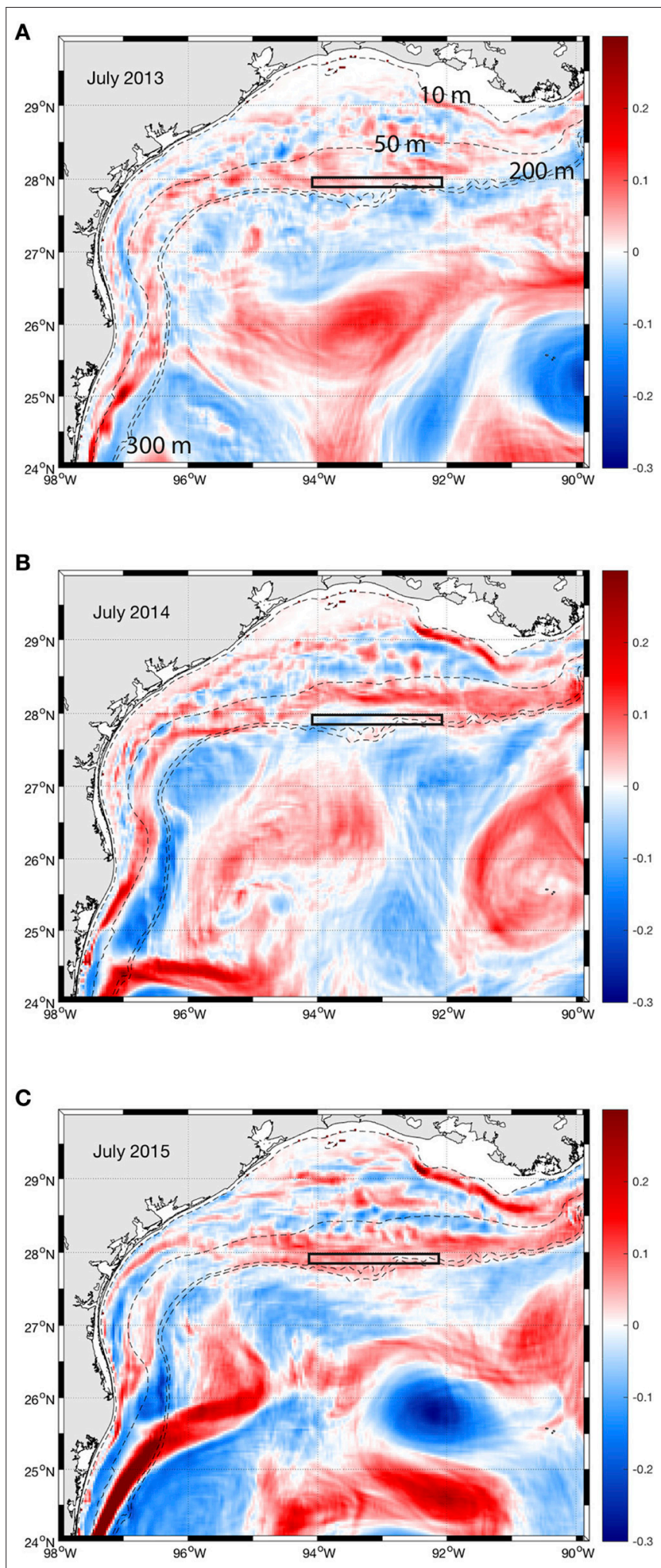

FIGURE 6 | Monthly mean normalized relative vorticity $(\zeta / f)$ at $10 \mathrm{~m}$ in the northwest Gulf of Mexico. $\zeta$ is the curl of the velocity and $f$ is the Coriolis parameter. Numbers show the isobaths depth. (A) July 2013. (B) July 2014. (C) July 2015. The black rectangle shows the location of the banks (West FGB, East FGB, Bright, Geyer, Mc Grail). 
data on M. cavernosa, our modeling approach used PLD and buoyancy data from another scleratinian species of the Caribbean region (i.e., O. faveolata). Although these two species are closely related, more studies on the larval life cycle of $M$. cavernosa are needed to improve our knowledge on its larval dynamics.

Isolated mesophotic reefs, such as the northwestern banks of the GOM, have a role in the persistence of coral reefs population as well as in the supply of larvae toward remote MCEs (Thomas et al., 2015). Findings on connectivity of $M$. cavernosa among banks of the NW GOM from our study and Studivan and Voss (2018; associate manuscript) study support the future management plan for expanding FGBNMS by including Bright, Geyer, and McGrail Banks. Moreover, the largescale dispersal patterns of $M$. cavernosa in the GOM observed in our study emphasizes the necessity of future connectivity research between all MCEs in the region using multiple species models to assess the possibility of establishing a regional conservation plan. Finally, our study associated with Studivan and Voss (2018; associate manuscript)'study show the relevance of combining modeling and genetic methods in investigating the connectivity patterns of marine populations for management purpose.

\section{DATA AVAILABILITY STATEMENT}

The data are available in the GitHub repository (https:/github. com/lgaravelli/data-cavernosa-dispersal).

\section{AUTHOR CONTRIBUTIONS}

LG, MS, JV, and LC designed the study. MS and JV provided the coral density and depth distribution data. AK and JF

\section{REFERENCES}

Acosta, A., and Zea, S. (1997). Sexual reproduction of the reef coral Montastrea cavernosa (Scleractinia: Faviidae) in the Santa Marta area, Caribbean coast of Colombia. Mar. Biol. 128, 141-148. doi: 10.1007/s0022700 50077

Aronson,. R. B., Precht,. W. F., Murdoch,. T. J. T., and Robbart, M. L. (2005). Longterm persistence of coral assemblages on the flower garden banks, northwestern gulf of Mexico: implications for science and management. Gulf Mex. Sci. 23, 84-94.

Bak, R. P. M., Nieuwland, G., and Meesters, E. H. (2005). Coral reef crisis in deep and shallow reefs: 30 years of constancy and change in reefs of Curacao and Bonaire. Coral Reefs 24, 475-479. doi: 10.1007/s00338-005-0009-1

Barron, C. N., Kara, A., Martin, P., Rhodes, R., and Smedstad, L. (2006). Formulation, implementation and examination of vertical coordinate choices in the Global Navy Coastal Ocean Model (NCOM). Ocean Model. 11, 347-375. doi: 10.1016/j.ocemod.2005.01.004

Bellwood, D. R., Hughes, T. P., Folke, C., and Nyström, M. (2004). Confronting the coral reef crisis. Nature 429, 827-833. doi: 10.1038/nature 02691

Bongaerts, P., Ridgway, T., Sampayo, E. M., and Hoegh-Guldberg, O. (2010). Assessing the "deep reef refugia" hypothesis: focus on Caribbean reefs. Coral Reefs 29, 309-327. doi: 10.1007/s00338-009-0581-x

Burgess, S. C., Nickols, K. J., Griesemer, C. D., Barnett, L. A. K., Dedrick, A. G., Satterthwaite, E. V., et al. (2014). Beyond connectivity: how empirical methods can quantify population persistence to improve performed the larval experiments in laboratory. LC provided the hydrodynamic model outputs. LG developed the larval dispersal model, performed the simulations, analyzed the data, and wrote the paper. All authors contributed to the final version of the manuscript.

\section{FUNDING}

This study was funded by the NOAA Office of Ocean Exploration and Research under awards NA09OAR4320073 and NA14OAR4320260 to the Cooperative Institute for Ocean Exploration, Research and Technology (CIOERT) at Florida Atlantic University-Harbor Branch Oceanographic Institute.

\section{ACKNOWLEDGMENTS}

We thank the NOAA/NOS National Centers for Coastal Ocean Science (NCCOS) for maps of predictable coral suitable habitat in the Gulf of Mexico and Emma Hickerson of FGBNMS for information on Montastraea cavernosa reproduction at East and West Flower Garden Banks. Samples of M. cavernosa for larval competency trials were collected under Broward County permit \#DAN1410-037 and Florida Fish and Wildlife Conservation Commission permit \#SAL-15-1645-SCRP. This is Contribution Number 2148 from Harbor Branch Oceanographic Institute at Florida Atlantic University.

\section{SUPPLEMENTARY MATERIAL}

The Supplementary Material for this article can be found online at: https://www.frontiersin.org/articles/10.3389/fmars. 2018.00174/full\#supplementary-material

marine protected-area design. Ecol. Appl. 24, 257-270. doi: 10.1890/130710.1

Chassignet, E. P., Hurlburt, H. E., Metzger, E. J., Smedstad, O. M., Cummings, J. A., Halliwell, G. R., et al. (2009). US GODAE: Global ocean prediction with the HYbrid Coordinate Ocean Model (HYCOM). Oceanography 22, 64-75. doi: 10.5670/oceanog.2009.39

Chérubin, L. M., and Garavelli, L. (2016). Eastern Caribbean circulation and island mass effect on St. Croix, US Virgin Islands: a mechanism for relatively consistent recruitment patterns. PLoS ONE 11:e0150409. doi: 10.1371/journal.pone.0150409

Davies, S. W., Strader, M. E., Kool, J. T., Kenkel, C. D., and Matz, M., $\mathrm{V}$ (2017). Modeled differences of coral life-history traits influence the refugium potential of a remote Caribbean reef. Coral Reefs 36, 913-925. doi: 10.1007/s00338-017-1583-8

DeBose, J. L., Nuttall, M. F., Hickerson, E. L., and Schmahl, G. P. (2013). A highlatitude coral community with an uncertain future: stetson bank, northwestern Gulf of Mexico. Coral Reefs 32, 255-267. doi: 10.1007/s00338-012-0971-3

Department of Commerce, National Oceanic and Atmospheric Administration (2015). Revisions of Boundaries for Flower Garden Banks National Marine Sanctuary; Intent To Prepare Draft Environmental Impact Statement. 15 CFR Part 922. Available online at: https://www.gpo.gov/fdsys/pkg/FR-2015-02-03/ pdf/2015-01949.pdf

Gaines, S. D., Lester, S. E., Grorud-Colvert, K., Costello, C., and Pollnac, R. (2010). Evolving science of marine reserves: new developments and emerging research frontiers. Proc. Natl. Acad. Sci. U.S.A. 107, 18251-18255. doi: 10.1073/pnas.1002098107 
Gardner, T. A., Côté, I. M., Gill, J. A., Grant, A., and Watkinson, A. R. (2003). Long-term region-wide declines in Caribbean corals. Science 301, 958-960. doi: $10.1126 /$ science. 1086050

Glynn, P. W. (1996). Coral reef bleaching: facts, hypotheses and implications. Glob. Chang. Biol. 2, 495-509. doi: 10.1111/j.1365-2486.1996.tb00063.x

Gough, M. K., Beron-Vera, F. J., Olascoaga, M. J., Sheinbaum, J., Jouanno, J., and Duran, R. (2018). Persistent Lagrangian transport patterns in the northwestern Gulf of Mexico. arXiv:1710.04027

Hastings, A., and Botsford, L. W. (2006). Persistence of spatial populations depends on returning home. Proc. Natl. Acad. Sci. U.S.A. 103, 6067-6072. doi: $10.1073 /$ pnas.0506651103

Hickerson, E. L., Schmahl, G. P., Johnston, M. A., Nuttall, M. F., Embesi, J. A., and Eckert, R. J. (2012). "Flower Garden Banks - A refuge in the Gulf of Mexico?" in Proceedings of the 12th International Coral Reef Symposium (Cairns, QLD).

Hinderstein, L. M., Marr, J. C. A., Martinez, F. A., Dowgiallo, M. J., Puglise, K. A., Pyle, R. L., et al. (2010). Theme section on "mesophotic coral ecosystems: characterization, ecology, and management”. Coral Reefs 29, 246-251. doi: 10.1007/s00338-010-0614-5

Hoegh-Guldberg, O., Poloczanska, E. S., Skirving, W., and Dove, S. (2017). Coral reef ecosystems under climate change and ocean acidification. Front. Mar. Sci. 4:158. doi: 10.3389/fmars.2017.00158

Holstein, D. M., Paris, C. B., and Mumby, P. J. (2014). Consistency and inconsistency in multispecies population network dynamics of coral reef ecosystems. Mar. Ecol. Prog. Ser. 499, 1-18. doi: 10.3354/meps10647

Holstein, D. M., Paris, C. B., Vaz, A. C., and Smith, T. B. (2015a). Modeling vertical coral connectivity and mesophotic refugia. Coral Reefs 35, 23-37. doi: 10.1007/s00338-015-1339-2

Holstein, D. M., Smith, T. B., Gyory, J., and Paris, C. B. (2015b). Fertile fathoms: deep reproductive refugia for threatened shallow corals. Sci. Rep. 5:12407. doi: $10.1038 /$ srep 12407

Hughes, T. P., Kerry, J. T., Álvarez-Noriega, M., Álvarez-Romero, J. G., Anderson, K. D., Baird, A. H., et al. (2017). Global warming and recurrent mass bleaching of corals. Nature 543, 373-377. doi: 10.1038/nature21707

Hughes, T. P., Anderson, K., Connolly, S. R., Heron, S. F., Kerry, J. T., Lough, J. M., et al. (2018). Spatial and temporal patterns of mass bleaching of corals in the Anthropocene. Science 359, 80-83. doi: 10.1126/science.aan8048

Jacobi, M. N., André, C., Döös, K., and Jonsson, P. R. (2012). Identification of subpopulations from connectivity matrices. Ecography 35, 1004-1016. doi: 10.1111/j.1600-0587.2012.07281.x

Johnston, M. A., Embesi, J. A., Eckert, R. J., Nuttall, M. F., Hickerson, E. L., and Schmahl, G. P. (2016). Persistence of coral assemblages at East and West Flower Garden Banks, Gulf of Mexico. Coral Reefs 35, 821-826. doi: 10.1007/s00338-016-1452-x

Kinlan, B. P., Poti, M., Etnoyer, P., Siceloff, L., Jenkins, C., Dorfman, D., et al. (2013). Digital data: Predictive models of deep-sea coral habitat suitability in the U.S. Gulf of Mexico. Downloadable digital data package. Department of Commerce (DOC), National Oceanic and Atmospheric Administration (NOAA), National Ocean Service (NOS), National Centers for Coastal Ocean Science (NCCOS), Center for Coastal Monitoring and Assessment (CCMA), Biogeography Branch. Released August 2013. Available online at: http:// coastalscience.noaa.gov/projects/detail?key=35

Ko, D. S., Preller, R. H., and Martin, P. J. (2003). "An experimental real-time intra Americas sea ocean nowcast/forecast system for coastal prediction," in Proceedings, AMS 5th Conference on Coastal Atmospheric and Oceanic Prediction and Processes (Washington, DC).

Kough, A. S., and Paris, C. B. (2015). The influence of spawning periodicity on population connectivity. Coral Reefs 34, 753-757. doi: 10.1007/s00338-015-1311-1

Lesser, M. P., Slattery, M., and Leichter, J. J. (2009). Ecology of mesophotic coral reefs. J. Exp. Mar. Biol. Ecol. 375, 1-8. doi: 10.1016/j.jembe.2009.05.009

Lett, C., Verley, P., Mullon, C., Parada, C., Brochier, T., Penven, P., et al. (2008). A Lagrangian tool for modelling ichthyoplankton dynamics. Environ. Model. Softw. 23, 1210-1214. doi: 10.1016/j.envsoft.2008.02.005

Locker, S. D., Armstrong, R. A., Battista, T. A., Rooney, J. J., Sherman, C., and Zawada, D. G. (2010). Geomorphology of mesophotic coral ecosystems: current perspectives on morphology, distribution, and mapping strategies. Coral Reefs 29, 329-345. doi: 10.1007/s00338-010-0613-6
Lugo-Fernández, A., Deslarzes, K. J. P., Price, J. M., Boland, G. S., and Morin, M. V. (2001). Inferring probable dispersal of flower garden banks coral larvae (Gulf of Mexico) using observed and simulated drift trajectories. Cont. Shelf Res. 21, 47-67. doi: 10.1016/S0278-4343(00) 00072-8

Menza, C., Kendall, M., and Hile, S. (2008). The deeper we go the less we know. Rev. Biol. Trop. 56, 11-24.

Nero, R. W., Cook, M., Coleman, A. T., Solangi, M., and Hardy, H. (2013). Using an ocean model to predict likely drift tracks of sea turtle carcasses in the north central Gulf of Mexico. Endanger. Species Res. 21, 191-203. doi: 10.3354/esr00516

Nunes, F. L. D., Norris, R. D., and Knowlton, N. (2011). Long distance dispersal and connectivity in amphi-Atlantic corals at regional and basin scales. PLOS ONE 6:22298. doi: 10.1371/journal.pone. 0022298

Oey, L., Ezer, T., and Lee, H. (2005). "Loop Current, rings and related circulation in the Gulf of Mexico: a review of numerical models and future challenges," in Circulation in the Gulf of Mexico: Observations and Models, eds W. Sturges and A. Lugo-Fernandez (Washington DC: American Geophysical Union), 31-56.

Pattengill-Semmens, C., Gittings, S. R., and Shyka, T. (2000). Flower Garden Banks National Marine Sanctuary: A Rapid Assessment of Coral, Fish, and Algae Using the AGRRA Protocol. Marine Sanctuaries Conservation Series MSD00-3. U.S. Department of Commerce, National Oceanic and Atmospheric Administration, Marine Sanctuaries Division, Silver Spring, MD.

Peliz, A., Marchesiello, P., Dubert, J., Marta-Almeida, M., Roy, C., and Queiroga, H. (2007). A study of crab larvae dispersal on the Western Iberian Shelf: physical processes. J. Mar. Syst. 68, 215-236. doi: 10.1016/j.jmarsys. 2006.11.007

Pineda, J., Hare, J. A., and Sponaugle, S. (2007). Larval transport and dispersal in the Coastal Ocean and consequences for population connectivity. Oceanography 20, 22-39. doi: 10.5670/oceanog.2007.27

Rippe, J. P., Matz, M. V., Green, E. A., Medina, M., Khawaja, N. Z., Pongwarin, T., et al. (2017). Population structure and connectivity of the mountainous star coral, Orbicella faveolata, throughout the wider Caribbean region. Ecol. Evol. 7, 9234-9246. doi: 10.1002/ece3.3448

Sammarco, P. W., Atchison, A. D., and Boland, G. S. (2004). Expansion of coral communities within the Northern Gulf of Mexico via offshore oil and gas platforms. Mar. Ecol. Prog. Ser. 280, 129-143. doi: 10.3354/meps 280129

Schmahl, G. P., Hickerson, E. L., and Precht, W. F. (2008). "Biology and ecology of coral reefs and coral communities in the flower garden banks region, Northwestern Gulf of Mexico," in Coral Reefs of the USA, eds B. M. Riegl and R. E. Dodge (Dordrecht, NL: Springer), 221-261. doi: 10.1007/978-1-4020-6847-8_6

Slattery, M., Leeser, M. P., Brazeau, D., Stokes, M. D., and Leichter, J. J. (2011). Connectivity and stability of mesophotic coral reefs. J. Exp. Mar. Biol. Ecol. 408, 32-41. doi: 10.1016/j.jembe.2011.07.024

Studivan, M. S., and Voss, J. D. (2018). Assessment of mesophotic coral ecosystem connectivity for proposed expansion of a marine sanctuary in the northwest Gulf of Mexico: population genetics. Front. Mar. Sci. 5:152.doi: 10.3389/fmars.2018.00152

Sutyrin, G. G., Rowe, G. D., Rothstein, L. M., and Ginis, N. I. (2003). Baroclinic eddy interactions with continental slopes and shelves. J. Phys. Oceanogr. 33, 283-291. doi: 10.1175/1520-0485(2003)033<0283:BEIWCS >2.0.CO;2

Szmant, A. M. (1991). Sexual reproduction by the Caribbean reef corals Monastrea annularis and M. cavernosa. Mar. Ecol. Prog. Series 74, 13-25. doi: 10.3354/meps074013

Thomas, C. J., Bridge, T. C. L., Figueiredo, J., Deleersnijder, E., and Hanert, E. (2015). Connectivity between submerged and near-sea-surface coral reefs: can submerged reef populations act as refuges? Divers. Distrib. 21, 1254-1266. doi: $10.1111 /$ ddi. 12360

Van Oppen, M. J. H., Bongaerts, P., Underwood, J. N., Peplow, L. M., and Cooper, T. F. (2011). The role of deep reefs in shallow reef recovery: an assessment of vertical connectivity in a brooding coral from west and east Australia. Mol. Ecol. 20, 1647-1660. doi: 10.1111/j.1365-294X.2011. 05050.x 
Voss, J. D., Williams, M. A., Reed, J. K., and Clark, R. (2014). "Benthic and fish communities in the mid and lower mesphotic zone of the sanctuary," in Fish and Benthic Communities of the Flower Garden Banks National Marine Sanctuary: Science to Support Sanctuary Management, eds R. Clark, J. C. Taylor, C. A. Buckel, and L. M. Kracker (Silver Spring, MD: NOAA Technical Memorandum NOS NCCOS 179), 201-260.

Vukovich, F. M., and Crissman, B. W. (1986). Aspects of warm rings in the Gulf of Mexico. J. Geophys. Res. 91, 2645-2660. doi: 10.1029/JC091iC02p02645

Zaron, E. D., Fitzpatrick, P. J., Cross, S. L., et al. (2015). Initial evaluations of a Gulf of Mexico/Caribbean ocean forecast system in the context of the Deepwater Horizon disaster. Front. Earth Sci. 9, 605-636. doi: 10.1007/s11707-014-0508-x
Conflict of Interest Statement: The authors declare that the research was conducted in the absence of any commercial or financial relationships that could be construed as a potential conflict of interest.

Copyright (๑) 2018 Garavelli, Studivan, Voss, Kuba, Figueiredo and Chérubin. This is an open-access article distributed under the terms of the Creative Commons Attribution License (CC BY). The use, distribution or reproduction in other forums is permitted, provided the original author(s) and the copyright owner are credited and that the original publication in this journal is cited, in accordance with accepted academic practice. No use, distribution or reproduction is permitted which does not comply with these terms. 